\title{
Food and Agricultural Industries: Opportunities for Improving Measurement and Reporting
}

\author{
by
}

\section{Richard Dunn \\ University of Connecticut}

\author{
Brent Hueth \\ University of Wisconsin-Madison
}

\section{CES 16-58 December, 2016}

The research program of the Center for Economic Studies (CES) produces a wide range of economic analyses to improve the statistical programs of the U.S. Census Bureau. Many of these analyses take the form of CES research papers. The papers have not undergone the review accorded Census Bureau publications and no endorsement should be inferred. Any opinions and conclusions expressed herein are those of the author(s) and do not necessarily represent the views of the U.S. Census Bureau. All results have been reviewed to ensure that no confidential information is disclosed. Republication in whole or part must be cleared with the authors.

To obtain information about the series, see www.census.gov/ces or contact J. David Brown, Editor, Discussion Papers, U.S. Census Bureau, Center for Economic Studies 5K034A, 4600 Silver Hill Road, Washington, DC 20233, CES.Papers.List@census.gov. To subscribe to the series, please click here. 


\begin{abstract}
We measure one component of off-farm food and agricultural industries using establishment level microdata in the federal statistical system. We focus on services for crop production, and compare measures of firm and employment dynamics in this sector during the period 1992-2012 with county-level publicly available data for the same measures. Based on differences across data sources, we establish new facts regarding the evolution of food and agricultural industries, and demonstrate the value of working with confidential microdata. In addition to the data and results we present, we highlight possibilities for collaboration across universities and federal agencies to improve reporting in other segments of food and agricultural industries.
\end{abstract}

Keyword: Data, Statistics, Industries and Markets

JEL Classification: A1, B2, C3

\footnotetext{
${ }^{*}$ Running title, "Measuring Food and Agricultural Industries.” We gratefully acknowledge financial support from Agriculture and Food Research Initiative Competitive Grant no. 2016-67024-24620, USDA National Institute of Food and Agriculture. Any opinions and conclusions expressed herein are those of the author(s) and do not necessarily represent the views of the U.S. Census Bureau. All results have been reviewed to ensure that no confidential information is disclosed.
} 
The National Agricultural Statistics Service provides timely, accurate, and useful statistics in service to U.S. agriculture.

— NASS mission statement

The National Agricultural Statistics Service (NASS) produces hundreds of statistical reports each year covering nearly all aspects of U.S. agricultural production. ${ }^{1}$ These efforts are directed almost entirely toward on-farm activities such as input use, production, input and output prices, farm income and finances, farmer demographics, and land use. ${ }^{2}$ Yet, the food-and-fiber supply chain stretches far beyond the farm gate, encompassing economic activity currently classified as manufacturing, transportation, warehousing, wholesale and retail trade, and services. Thus, to adequately study the universe of economic activity associated with food and agriculture-what we term food and agriculture industries (FAI) - requires a statistical reporting framework that spans traditional industrial classification structures.

Presently, however, there is no coordinated reporting on FAI in the United States. Offfarm economic activity is largely outside the current scope of NASS responsibility, but as a result of technological change and evolution in industry structure, this is where much of FAI activity lies. While other federal statistical agencies, notably the Bureau of Labor Statistics (BLS) and Census Bureau, report economic activity in off-farm industries, the usefulness of these statistics with respect to FAI is limited by structure of the current industrial classification system, the reporting requirements that generate the underlying data, and the data processing methods the agencies employ. Without a specific mandate to report on food and agriculture, these agencies have had little reason to overcome these issues and

\footnotetext{
${ }^{1}$ This article is unavoidably acronym-dense; for ease of reference, we provide a list abbreviations in the appendix

${ }^{2} \mathrm{~A}$ notable exception is the Cotton Ginning survey, which surveys all active cotton gins in 17 states on a semi-monthly basis to collect the number of bales ginned to date, an estimate of how many more they expect to gin during the season, and the average price paid to producers for cottonseed.
} 
undertake systemic reporting of off-farm FAI activity. ${ }^{3}$ In our opinion, this is unlikely to change given continued reductions in budgets for federal statistical agencies.

The potential ramifications of failing to report systematically on FAI are far-reaching. First, some of the most important contemporary public policy debates are directly linked to food and agricultural production, including the environmental consequences of modern food production systems, the relationships between food consumption behavior and human health, immigration, and global trade. However, policies designed to address any of these issues must also take into consideration decisions that occur well beyond the farm gate. Even basic notions regarding productivity changes in agriculture may merit reconsideration in light of shifting organizational boundaries for farm operations. There was a time when "farming" and "agriculture" were nearly synonmous. Still today these words are often used interchangebly, even while much of agriculture has moved off farm. Shumway et al. (2016) provide an extensive evaluation and set of recommendations for updating and improving productivity measurement of the agricultural sector as represented by farm-level data. Productivity changes profitability of farms will influence other FAI sectors and effects felt upstream and downstream from the farm can have important feedback effects on agricultural producers. At present, we lack the data necessary to examine the effects of policy on the whole of FAI, and our understanding of linkages between productivity changes in agriculture and the broader economy is necessarily limited.

Second, as an increasing share of value added from FAI is generated beyond the farmgate, failing to document the full contribution of FAI to the US economy may result in less public support for all activities related to food and agricultural production. For example, with increasingly limited government resources, undercounting the number of businesses and jobs attributable to FAI weakens the argument for funding to support research on the agricultural supply chain and the structure of agricultural production and labor markets.

\footnotetext{
${ }^{3}$ The National Agricultural Workers Survey (NAWS) is a notable exception. The Department of Labor, which conducts the survey, gathers information about individuals engaged in crop production (establishments with NAICS code 111), or agricultural support services for crop production (NAICS code 1151).
} 
Possibly reductions of this sort are justifiable as a matter of public policy, but such a determination should be the outcome of well-informed debate, rather than a response to institutional intertia and a growing misalignment of responsibilities among the agencies that comprise the U.S. Federal Statistical System.

In this article, we describe a recently initiated data collection effort and discuss possibilities for a long-run collaborative research program to address this significant gap in our knowledge of FAI. Creating new data collection and reporting infrastructure for FAI would be an enormous undertaking for USDA, requiring substantial new funding from Congress. We do not expect this will occur. Fortunately, however, significant improvements in FAI reporting are feasible now using existing data collected by the Census Bureau and Internal Revenue Service (IRS). We contend that the expansion of the Federal Statistical Data Research Center (FSRDC) system to an increasing number of land-grant universities presents an opportunity to forge new institutional partnerships and research collaborations among government agencies, academic researchers, and industry stakeholders. ${ }^{4}$

We aim to demonstrate the tangible value of such efforts by presenting new results describing one component of FAI: agricultural support services (AS) for crop production. As we outline subsequently, AS has long been recognized as an important, but understudied component of agricultural production in the United States. Therefore, we compare estimates of the number of establishments engaged in AS constructed from various public and restricted-use data sets (the U.S. Census Bureau uses the term establishment in reference to a physical location or address where economic activity takes place; it reserves the term firm exclusively to reference a collection of one or more establishments under a common ownership structure. This results we report here will help illustrate both the shortcomings

\footnotetext{
${ }^{4}$ The FSRDC system, which began as a handful of remote locations where sworn researchers could access Census microdata, has grown to 25 locations with substantial continued growth expected during at least the next several years. Recent administrative and legislative authority emphasizing the need for greater use of administrative data as a source of statistical information on people and the economy, and for increased interagency data sharing to expand opportunities for valuable data linking, have provide further motivation to open and expand the system (Milner 2016).
} 
of existing public-use data products and the potential benefits of restricted-use data available at FSRDC facilities. We also provide the first estimates of establishment entry and exit into AS and the relative importance of multi-establishment firms in this sector.

\section{Measuring Food and Agriculture Industries}

Presently, there is neither an operational definition of FAI within the federal statistical system nor a coordinated system of reporting on FAI. ${ }^{5}$ Without this framework for data collection and analysis, it is impossible to assemble accurate statistics about the total contribution of FAI to the US economy. And, without such statistics, we lack the inputs necessary to analyze the industry-wide impacts of policy interventions and economic shocks.

Any new reporting framework for FAI must arise within the structure of the existing industrial system currently utilized by federal statistic agencies, the North American Industry Classification System (NAICS). NAICS is a hierarchical system that categorizes 813,999 unique economic activities. In the latest NAICS (2012) edition, these activities are aggregated into 1,065 mutually exclusive six-digit industry codes-the finest level of disaggregation reported in Census products. Of these, there are 168 industry categories that only include establishments engaged in activity associated with FAI, e.g., Soybean Farming (111110), Farm Management Services (115116), Fresh Fruit and Vegetable Merchant Wholesalers (424480). Yet, NASS reports on just 56 of these 168 six-digit industries. Further, there are a significant number of six-digit industries that include economic activity associated with FAI, but are not exclusive to such activity, e.g., Nursery, Garden Center, and Farm Supply Stores (444220) and Long-Distance Specialized Freight Trucking (484230).

Identifying, classifying, and validating the activity of firms across each of these sixdigit industries would be far too large a project for any one research team. In this paper,

\footnotetext{
${ }^{5}$ Marion and Others (1986) synthesize work by the regional research group NC 117 that organized its activities around systematic sector-based study of farm production, marketing, and retailing to final consumers. This group did not consider upstream activities, and never had access to the firm- and establishmentlevel microdata that are available today in the newly launched inter-agency network of Federal Statistical Research Data Centers (census.gov/fsrdc) described in greater detail below.
} 
we take a step in this direction by examining one small component of FAI: agricultural support services (AS) for crop production. We begin the description of FAI with these establishments for a number of reasons:

First, they provide services that were historically undertaken directly by farm operators (e.g. soil preparation, planting, harvesting, storage, management and hiring labor). As the nearest upstream and downstream linkages to the farm in the food-and-fiber supply chain, they are a natural starting point when constructing a data reporting framework that joins agricultural production to the non-farm agricultural economy.

Second, the emergence of such enterprises, and the resulting redefinition of the operational boundary of the farm, has been recognized as an important phenomenon requiring study for at least 50 years (Mighell and Jones 1963; Breimyer 1964; Davidson and Mighell 1964). In particular, widely-accepted stylized facts about farms may yet fail to accurately portray the entirety of agricultural production. For example, the Economic Research Service (ERS) reports that hired and self-employed labor has decreased at roughly $2 \%$ per year since 1948 (Economics Research Service 2016). The implications of this decline for the overall contribution of agricultural production to productivity changes in the general economy are very different depending on whether there has been a corresponding increase in employment at AS establishments.

Third, the production activities that comprise AS not only straddle firm boundaries and industry definitions, but entire reporting structures. Although AS establishments are directly engaged in on-farm agricultural production activity, they are not farms and thus are excluded from the Census of Agriculture. At the same time, they are not currently within scope for the Economic Census. This unique status has generated a knowledge gap that is especially difficult to fill.

Therefore, using the specific case of AS to demonstrate how existing data sources can be harnessed to improve understanding of FAI in general yields important new insights specific to agricultural production in the United States. Of course, this is intended only as 
an illustration-a proof of concept. Extending data collection to the entirety of FAI will require substantial coordination among researchers and cooperation across universities and federal statistical agencies, a topic we address in a subsequent section.

\section{Agricultural Support Services}

Data collection on agricultural service activity has long been recognized as integral to understanding agricultural production in the United States:

Until the 1940's, agriculture in America was largely self-reliant in regard to many production and harvesting practices now available from off-farm sources in the form of agricultural services. During the last three decades agricultural services have become an increasingly specialized industry. The technological and scientific changes in American agriculture have been directly related to the development of the agricultural service industry. A census of this industry is essential to provide facts necessary for:

A) Broader view of today's farm production.

B) Better understanding and interpretation of long-term agricultural changes and trends.

C) More meaningful analysis of the interrelationships of agriculture and agricultural services.

1974 Census of Agriculture, Volume III: Agricultural Services, Appendix A, Page A-1.

Despite the sentiments expressed above, concerted attempts by federal statistical agencies to compile information on establishments primarily engaged in agricultural support services ceased following the 1978 Census of Agriculture because of federal budgetary pressures during the early 1980 s. $^{6}$

The obstacles preventing the resuscitation of such data collection efforts are manifest. Most obviously, the funding pressures faced by federal statistical agencies that ultimately

\footnotetext{
${ }^{6}$ The Census of Agriculture continues to collect information on income from agricultural support services if it is a secondary source of farm income.
} 
lead to the demise of the Census of Agricultural Services are still present. In addition, there are numerous structural barriers within the federal statistical system that would significantly impede the creation of new, large-scale, systematic collection program focused on establishments and firms engaged in agricultural support services.

First, the Economic Census has never included establishments engaged in agricultural support services: every Census of Agricultural Services (1969, 1974 and 1978) was conducted as part of the Census of Agriculture. As a result, the Census Bureau currently lacks the infrastructure, institutional knowledge, financial resources, and urgency to begin new survey efforts directed towards these industries.

Second, NASS would face substantial challenges constructing a reliable and accurate sampling frame of agricultural support services establishments. Although the NASS sample frame is used to produce over 400 survey products, including the Census of Agriculture, it does not currently include the universe of agricultural services establishments. While there are numerous possible methods to expanding the NASS sample frame to capture these establishments, it is worth noting that NASS has never used federal tax information-the approach adopted by the Census Bureau-for this purpose.

Specifically, under 26 USC 6103(j)(1), the Department of Commerce is authorized to use information from IRS payroll and income tax records in "the structuring of censuses and national economic accounts and conducting related statistical activities authorized by law." Indeed, from 1969 until 1997, the sample frame for the Census of Agriculture was largely based on these tax records. ${ }^{7}$ Although 26 USC Section 6103(j)(5) similarly authorizes the Department of Agriculture to use federal tax records for the purpose of "structuring, preparing, and conducting the census of agriculture," the NASS sample frame does not incorporate this information.

\footnotetext{
${ }^{7}$ The presence of agricultural production activity can be inferred from reports of farm income on IRS Form 1040F, income of a sole-proprietorship from IRS Form 1040C, income tax of an S-corporation from IRS Form 1120S, return of partnership income from IRS Form 1065, and federal payroll withholding from IRS Forms 941 and 943.
} 
With little prospect of a Census of Agricultural Services joining the existing portfolio of data products compiled by either the Census Bureau or NASS, reporting on the AS sector will require the use of data already being collected by federal statistical agencies. Fortunately, considerable data now exist to study this (and other relevant) sector, though much of it is buried within and among various NAICS categories that were not developed specifically for the purpose of measuring FAI.

\section{Current Data Resources}

Despite the absence of a dedicated data collection program focused on establishments engaged in agricultural support services, there are numerous information sources utilizing administrative records collected by other state and federal agencies that can be used to study the economic behavior of such enterprises.

\section{Publicly available data}

There are several federal data programs that publish information about the economic activity of establishments and firms engaged in agricultural support services as part of wider efforts to document the characteristics of workers and firms in the US economy. The data itemized below are publicly available over the internet, either as flat files for download, or through web-based applications that generate custom tables.

- County Business Patterns (CBP). The CBP is an annual series produced by the Census Bureau that includes the number of active establishments, employment during the week of March 12, first quarter payroll, and annual payroll. This information is extracted from the Business Register, a database maintained by the Census Bureau that includes all domestic establishments, excluding private households and government entities. Statistics are published at different levels of geographic disaggregation (nation, state, metropolitan area, county, and zip code) for industrial classifications down to six-digit NAICS categories. It is worth noting that the CBP is constructed 
strictly from the full six-digit NAICS level. That is, an establishment that is assigned the NAICS code 115100 will not be included in the published totals for agricultural support services for crop production because it does not have a six-digit industry code between 115111 and 115116 .

- Quarterly Census of Employment and Wages (QCEW). The QCEW is a cooperative program involving the Bureau of Labor Statistics (BLS) and state agencies that oversee unemployment insurance (UI). Through these partnerships, the QCEW provides monthly employment and quarterly wage information for nearly all workers covered under state and federal UI programs. Statistics are published at different levels of geographic disaggregation (nation, state, metropolitan area, county, and zip code) for industrial classifications down to six-digit NAICS categories.

- Quarterly Workforce Indicators (QWI). The QWI provides information on employment, payroll, wage, and job flows based on worker and firm characteristics. It is one product stemming from the Local Employment Dynamics (LED) Partnership. Under this partnership, states agree to share UI and QCEW information with the Longitudinal Employer-Household Dynamics (LEHD) Program at the Census Bureau, which then combines the information with other administrative and survey data. Statistics are publicly available at varying levels of geographic and industry disaggregation, and according to characteristics of firms (age) and workers (gender, age).

\section{Restricted Use Data}

Interested researchers can access the establishment- and firm-level microdata that underlie the public-use data products described above by following the application procedures developed at the appropriate federal statistical agency. An additional data product that offers 
establishment and firm-level microdata, but that does not have a publicly available counterpart covering agricultural support services, is the Longitudinal Business Database (LBD) ${ }^{8}$

The LBD is an annual series produced by the Census Bureau based on establishment records from the Business Register (Jarmin and Miranda 2002). Thus, it uses the same microdata as the CBP, but with three notable additions. First, researchers at the Census Bureau Center for Economic Studies (CES) have linked establishment records over time, generating a nearly 40 year panel that includes all non-farm establishments with paid employees. Second, establishments are linkable to information collected in other Census datasets through a unique identifier. Third, establishments are linked to parent firms by incorporating information from the Company Organization Survey (COS).

Over the past 15 years, the LBD has become the workhorse dataset for studying the characteristics and determinants of entry, growth, and exit at the establishment, firm, industry, and economy-wide level (e.g., Foster, Haltiwanger, and Krizan 2002, Foster, Haltiwanger, and Krizan (2006), Davis, Faberman, and Haltiwanger (2006), Giroud and Mueller (2015), Acemoglu et al. (2013), Haltiwanger, Jarmin, and Miranda (2013)). Longitudinal establishment-level data that encompass an entire state or regional economy are increasingly available in other countries, and are being used by economists to link empirical research across studies of labor markets, industrial organization, trade, and aggregate fluctuations (e.g., Syverson 2004, Abowd et al. (2009), Bernard et al. (2010), Oberfield and Raval (2014))

In the subsequent section, we present new results characterizing the economic activity of establishments engaged in agricultural support services for crop production based on the restricted-access data available in LBD and the Business Register.

\footnotetext{
${ }^{8}$ The Business Dynamics Statistics (BDS) program reports establishment, employment, payroll, and job flow information based on the LBD, but only at the two-digit level. Thus, the BDS publishes such information for establishments engaged in agriculture (NAICS 11) and manufacturing (NAICS 31-33), but not separately for agricultural support services (NAICS 115).
} 


\section{Agricultural Support Services for Crop Production}

The top panel of figure 1 presents the number establishments engaged in agricultural support services for crop production from the CBP (1998-2014) and the QCEW (2002-2014). The difference in these two series is dramatic — the number of establishments reported from the CBP is almost half the number reported from QCEW - and illustrate several key differences in the underlying structure of each data product. ${ }^{9}$ Recall that the sample frame for the CBP is based on the Business Register, which receives employment and payroll information from IRS payroll tax filings. The Business Register includes the universe of private establishments, but the scope of the CBP itself does not cover agricultural production workers. ${ }^{10}$ In contrast, no such scope restriction exists for the QWEC.

Thus, one potential explanation for the differences depicted in figure 1 is the subtle distinction between classifying an establishment as belonging to an agricultural production industry and classifying the individual employees of an establishment as agricultural production workers. For example, if a strawberry farmer hired a laborer to harvest his field, then that worker would be an agricultural production worker for an establishment in an agricultural production industry (NAICS 111333: Strawberry Farming). If instead that worker were hired by a farm labor contractor and assigned to pick strawberries for a client farm, the laborer would be classified as an agricultural production worker in a non-agricultural production industry (NAICS 115115: Farm Labor Contractors and Crew Leaders).

Whether the farm labor contractor is in-scope for the CBP then depends on whether it has any employees that are not agricultural production workers. If the business is organized as a sole proprietorship and the contractor-owner is the only individual that is not an agricultural production worker, then the establishment is out-of-scope. If the same business were instead organized as an S-Corporation and the contractor were treated as an employee not

\footnotetext{
${ }^{9}$ The following discussion is focused on the specific attributes of establishments engaged in agricultural support services. Becker et al. (2005) provide a more general discussion of differences in the sample frames used by the Census Bureau and BLS.

${ }^{10}$ Other excluded worker categories are: self-employed, domestic service workers, most government employees, and employees on ocean-borne vessels or in foreign countries.
} 
engaged in agricultural production activity, then the establishment would be in-scope with one employee for CBP reporting purposes. Similarly, if the business were a sole proprietorship, but hired an administrative assistant to handle office tasks, then it would be in-scope with one employee for CBP reporting purposes. The failure to account for agricultural production workers, and thus establishments that only employ agricultural production workers, must be recognized as a serious limitation of the CBP data for studying economic activity in agricultural support services.

Yet, the QCEW is not without its own disadvantages. The reporting requirements for wages paid to agricultural production workers are far stricter than the reporting requirements for federal unemployment insurance for such workers. Specifically, employers must file IRS Form 943 annually if they paid wages to one or more farmworkers and the wages were subject to social security and Medicare taxes or federal income tax withholding. All cash wages paid to a farmworker are subject to social security and Medicare taxes and federal income tax withholding if that employee receives cash wages of more than $\$ 150$ during the calendar year, or if the total (cash and noncash) wages paid to all farmworkers is $\$ 2,500$ or more.

In contrast, employers engage the federal unemployment insurance system under two conditions set forth in the Federal Unemployment Tax Act (FUTA). Employers must pay federal unemployment tax if the total of wages paid to workers is at least $\$ 20,000$ in any calendar quarter. Employers must also pay federal unemployment tax if in each of 20 different, though not necessarily consecutive calendar weeks in the current or preceding calendar year, there was at least one day in which they had ten or more employees performing service in agricultural labor. It is important to recognize that QCEW is compiled from state reports and state requirements for unemployment taxes can be stricter than those established under FUTA. Nonetheless, it should be obvious that small employers of agricultural production workers can potentially organize work schedules to legally avoid contributing to the unemployment insurance system, though they would still be legally required to with- 
hold income, social security, and Medicare taxes. Such establishments would appear in the Business Register, though not the QCEW (if they avoid contributing to the UI system).

The above discussion suggests reasons that both the CBP and QCEW would tend to undercount economic activity in the agricultural support services sector. Yet, other attributes of the QCEW would tend to overstate establishment counts. Notably, establishments remain in the QCEW until they exhibit three consecutive quarters with zero employment. Thus, an establishment that ceased operation in August 2002 would still count toward the establishment total for 2003.

A final difference between the CBP and the QCEW that could explain the very different establishment counts rests on the assignment of establishments to industrial categories. The BLS collects information on industry classification through the Annual Refiling Survey (ARS). The ARS is sent to approximately one-third of the businesses with at least four employees included in the BLS sample frame on a rotating basis. Thus, most businesses are requested to verify or update their primary activity every three years. These responses are used to assign industry within the QCEW. In contrast, the Census Bureau assigns industry classifications to establishments in the Business Register through several mechanisms. For new establishments, the Census Bureau links tax records from the IRS with industry assignments from the Social Security Administration (SSA) using the unique employer identification number (EIN). ${ }^{11}$ The initial industry assignment is then updated with the receipt of new information from Census surveys, e.g., responses to the Economic Census. Periodically, the accuracy of industry assignments is improved by comparing those assigned by the Census Bureau with those assigned by BLS.

Based on the preceding considerations, the bottom panel of figure 1 presents a time-series of establishment counts constructed from the restricted-access, establishment-level infor-

\footnotetext{
${ }^{11}$ This file is known as the Employer Classification File. The collection of industry information for statistical purposes dates to the first enumeration of employers covered under the Federal Insurance Contributions Act (FICA). Although enumeration of covered employers is now the responsibility of the IRS, the collection of employer industry classification remains under the SSA. Dill (1992) provides a detailed history of the collection and use of industry information by the SSA.
} 
mation collected from payroll tax filings and contained in the LBD and Business Register. It includes all establishments with paid employees classified as support services for crop production without regard to whether all or some or none of their employees were engaged in agricultural production. ${ }^{12}$ Thus, it combines aspects of the CBP series (based on IRS tax filings) with attributes of the QCEW series (includes workers engaged in agricultural production).

This series provides establishment counts that are closer to those based on the QCEW. At the same time, however, the recent trend of contraction evident in the CBP series is also apparent. Taken together, these results suggest potentially serious measurement error issues in available public-use data covering agricultural services. Knowing the number of establishments engaged in agricultural support services is clearly important for documenting the contribution of this sector to the overall economy. For that purpose, the CBP is clearly inadequate, while the QCEW may be sufficient. For studying changes in the number of establishments, however, the QCEW appears to have significant disadvantages. It is not immediately clear why the QCEW lacks the trend observed in the restricted-access microdata, but reconciling this difference is an obvious area of research that deserves attention in future work.

To summarize, the results presented here demonstrate that the seemingly simple problem of accurately counting the number of operating businesses engaged in agricultural services on a year-to-year basis is far from resolved. Disconcertingly, answers based upon publicly available date vary greatly depending on the source employed. In part, this question remains open because no federal statistical agency has a clear mandate to produce an accurate accounting for this particular group of industries. But, our results also demonstrate that

\footnotetext{
${ }^{12}$ The data have been processed to generate, when reasonable, industry classifications at the 4-digit NAICS level if such information was missing. For example, an establishment assigned NAICS 000000 (unknown industry) in their year of entry; NAICS 110000 (agriculture, forestry, fishing, and hunting) in their second year; NAICS 115000 (support services for agriculture and forestry) in their third year; and NAICS 115113 (crop harvesting, primarily by machine) in all subsequent years is assigned to agricultural support services for crop production (NAICS 1151) for all years.
} 
the establishment-level microdata available to researchers with approved FSRDC projects could provide productive opportunities moving forward.

\section{Establishment Dynamics}

The decrease in the number of establishments engaged in agricultural support services observed in the IRS payroll data could reflect either an increase in the rate of establishment birth or a decrease in the rate of establishment death (the terms entry and birth are interchangeable; analogously with exit and death). For example, the steady decline in the number of farms in the United States is a well-documented ongoing phenomena that began decades ago as farmers have either ceased production activities or sold land as assets to other farmers who formed larger operations (Alston et al. 2010). These dynamics reflect an exit rate that has been persistently higher than the entry rate.

More generally, an increasing number of studies are finding that the birth rate of new businesses has fallen substantially over the past two decades (Haltiwanger, Jarmin, and Miranda 2013; Gourio, Messer, and Siemer 2016; Lee and Mukoyama 2015). Perhaps most notable has been the decline in technology start-ups (Decker et al. 2016; Prescott and Ohanian 2014). To our knowledge, however, establishment dynamics in the agricultural support services sector have not been documented. Using the restricted-access, establishment-level microdata in the LBD, we constructed annual entry and exit rates for establishments engaged in support services for crop production from 1992 to $2012 .^{13}$

It is clear from the two panels of figure 2 that there is significant decline in the birth rate since 1998, while the death rate remained fairly constant, even through the Great Recession. This pattern is true regardless whether we consider establishments that are ever classified as agricultural support services for crop production (top panel) or restrict the sample to

\footnotetext{
${ }^{13}$ Because the LBD has never been explicitly used to address this question, the LBD birth and death flags underwent extensive validation checks using the underlying Business Register records to conduct matching on EIN, name, and geographic location.
} 
establishments that are classified as agricultural support services for crop production in the year of birth or death (bottom panel).

Documenting a decline in the birth rate of establishments in agricultural support services is an important new finding. The increasing availability of micro data permits researchers to study the turbulent underpinnings characterizing establishment-level dynamics that ultimately lead to economy-wide productivity growth or decline. Analyses of entry and exit, growth and contraction, are capable of providing the Schumpeterian metaphor of creative destruction with a concrete empirical structure never before possible. An important area of research moving forward will be explaining why entry rates have fallen so dramatically over the past decade.

\section{Contraction and Consolidation}

Prior results based on restricted-access data demonstrated that the number of establishments engaged in agricultural support services for crop production has declined over time. In this subsection, we explore how the average size of active establishments has changed over time. Figure 3 plots the average number of employees per establishment using data from the CBP and QCEW. The CBP only provides employment counts for the week including March 12, whereas the QCEW provides employment counts for every month. For the purposes of comparison, we include the QCEW employment and establishment count data for March. Because of potential seasonality in labor demand, we also use the analogous data for June and September. Three patterns stand out:

First, these plots indicate significant seasonality in employment. From the QCEW, the number of employees per establishment in June is approximately 29 percent larger than the number of employers per establishment in March.

Second, agricultural production workers account for a substantial share of total employment. Comparing the CBP and QCEW series for March employment, agricultural production workers account for 45 percent of total employment. To the extent that employment of 
workers engaged in agricultural production exhibits greater seasonality than employment of workers not engaged in agricultural production, this comparison would understate the share of agricultural production workers in total employment.

Third, regardless of the data source or period considered, the average size of establishments is clearly increasing over time. The QCEW data reveals that the total number of employees per establishment increased between 13 percent and 19 percent from 2001 to 2014. The CBP data imply that the average number of employees not engaged in agricultural production at an agricultural support services establishment increased 27 percent over the same time period.

A decrease in the total number of establishments coupled with an increase in the average number of employees per establishment suggest that consolidation at the establishmentlevel has occurred in agricultural support services. An important related question is whether consolidation has also occurred at the firm-level. The microdata available in the LBD, which includes both unique establishment and firm identifiers, can be used to examine whether multi-establishment firms have increased their share of total activity in agricultural support services. Figure 4 plots the percentage of all establishments in agricultural support services for crop production that are associated with a multi-establishment firm. It is clear that while consolidation is occurring at the establishment-level, it is not occurring at the firm-level. The proportion of establishments from multi-establishment firms has fluctuated within a narrow band for at least the past two decades.

\section{Opportunities for Greater Data Linkages}

Thus far, we have discussed ways in which existing data collected by federal statistical agencies can be used to study the economic behavior of establishments and firms involved in agricultural support services. In this section, we highlight how greater integration of data across federal statistical agencies could provide valuable new information to address issues raised earlier. 


\section{Labor Markets in Agricultural Support Services}

Businesses providing agricultural support services to farm operations are employing two classes of workers: those engaged in agricultural production and those not engaged in agricultural production. While the labor markets for each worker type may be related, they are nonetheless distinct. Therefore, understanding employment dynamics-the sources of job growth and destruction, as well as the evolution of wages earned-in these industries will require data that allows researchers to study each worker type separately.

Because most employers are required to report income and payroll tax withholding for non-agricultural production workers on a quarterly basis (using IRS Form 941), the payroll information included in the Business Register can provide a valuable source of information about AS workers not engaged in agricultural production. In contrast, employers are only required to report income and payroll tax withholding for agricultural production workers on an annual basis (using IRS Form 943). Given the clear seasonality in labor demand for agricultural production workers, data from the Business Register that provides employment information for only one point during the year are of limited value for studying these workers.

This example highlights the challenge that researchers face when relying on one source of administrative data, even one as comprehensive as payroll tax filings. Such data can help answer some, but not all, questions. Nevertheless, we believe that linking existing administrative data collected by different federal statistical agencies can ameliorate the particular shortcomings exhibited by any one data source. For example, by combining the quarterly employment and payroll information for workers not engaged in agricultural production from the Business Register with monthly information on total employment and payroll that is currently collected by states administering UI programs (and reported to both BLS and the Census Bureau), a more complete picture of employment in AS will emerge. 


\section{Establishment Dynamics}

Results reported earlier demonstrated a marked decrease in the entry rate of new establishments into agricultural support services. Understanding the causes of this slowdown in entry stands as a central research question moving forward. Providing answers will require identifying how new establishments arise. One reasonable hypothesis is that farm operators initially provide these services to themselves. The purchase of new capital may then lead them to offer these services to a limited number of neighboring farm operators to spread overhead cost. At some point, service provision becomes a sufficiently important source of income that it is spun-off as a separate business.

The Census of Agriculture, which includes questions about capital purchases and farmrelated income from providing agricultural services, potentially offers the necessary information to test whether this hypothesis is correct and whether this source of new business formation has changed over time. Doing so would be possible by linking establishment records in the LBD to farm responses from preceding Censuses of Agriculture. In addition to documenting how new agricultural support service establishments arise, such a linkage would allow researchers to better investigate whether agricultural support services are a complement to agricultural production or a substitute economic activity.

\section{Concluding Thoughts}

The need for better reporting on the contribution of food and agricultural industries to the US economy should be a central concern to agricultural economists, statistical agencies, business groups, and federal, state, and local policymakers. There are questions we simply cannot answer because we lack data or lack coordination of data reporting across statistical agencies. Perhaps just as important, this lack of data and coordination obscures questions we do not yet know need to be asked. Budgets for data collection are already stretched, thus efficiencies that can be realized through better use of existing data must be a priority. 
We have attempted to demonstrate the potential benefits of using establishment-level microdata currently collected by the Census Bureau and Bureau of Labor Statistics to study agricultural support services for crop production. These results represent the first foray into this literature using part of the non-farm FAI sector of the U.S. economy. We have examined just one small piece of FAI, but it is the natural starting point for this work, because the sector is immediately adjacent to farm-level activity, and because of its unusual status as an industrial sector without a home in the federal statistical system. Having taken this first step, we are confident that continued use of administrative and survey microdata will generate both additional insights and exciting new research agendas.

The opportunities available to agricultural economists to engage with these data are increasing rapidly. In 2012, Census Data Research Centers were operating on the campus of three land-grant universities: Cornell, Minnesota, and UC Berkeley. In addition, a small group of consortia existed to provide access to nearby centers: North Carolina State (RTI); Georgia and Tennessee (Atlanta Fed); Illinois (Chicago Fed); Michigan State (University of Michigan Institute for Social Research). Since 2012, Federal Statistical Research Data Centers ${ }^{14}$ or branches have been established at several additional land-grant universities including, Wisconsin, Nebraska (also serving Iowa State), Missouri, Maryland, Pennsylvania State, Illinois, and Texas A\&M. In 2017, two new centers will open at Kentucky and Colorado (serving Colorado State) and other universities are actively engaged in discussions with Census to apply for siting with new.

There now are many opportunities to share knowledge across research groups, and to build data infrastructure that will improve and deepen our collective professional capacity for participating in policy matters and contributing high quality information.

\footnotetext{
${ }^{14}$ The renaming, replacing "Census" with "Federal" was an explicit response by Census to encourage greater inter-agency data sharing.
} 


\section{References}

Abowd, J.M., B.E. Stephens, L. Vilhuber, F. Andersson, K.L. McKinney, M. Roemer, and S. Woodcock. 2009. "The LEHD infrastructure files and the creation of the Quarterly Workforce Indicators." In Producer Dynamics: New Evidence From Micro Data. University of Chicago Press, pp. 149-230.

Acemoglu, D., U. Akcigit, N. Bloom, and W.R. Kerr. 2013. "Innovation, Reallocation and Growth.” Working paper, National Bureau of Economic Research.

Alston, J.M., M.A. Andersen, J.S. James, and P.G. Pardey. 2010. “A Brief History of U.S. Agriculture." In Persistence Pays: U.S. Agricultural Productivity Growth and the Benefits from Public R\&D Spending. 2002, pp. 9-22.

Becker, R., J. Elvery, L. Foster, C.J. Krizan, S. Nguyen, and D. Talan. 2005. “A Comparison of the Business Registers Used by the Bureau of Labor Statistics and the Bureau of the Census.” In Joint Statistical Meetings.

Bernard, A.B., J.B. Jensen, S.J. Redding, and P.K. Schott. 2010. "Wholesalers and Retailers inUs Trade." The American Economic Review 100:408-413.

Breimyer, H.F. 1964. "Future Organization and Control Of U.S. Agricultural Production and Marketing." Journal of Farm Economics 46:930-944.

Davidson, J.R., and R.L. Mighell. 1964. "Research on Coordination of Farm and Nonfarm Stages of Productionthe Need is Now." Journal of Farm Economics 46:489-491.

Davis, S.J., R.J. Faberman, and J. Haltiwanger. 2006. "The Flow Approach to Labor Markets: New Data Sources and Micro-Macro Links." The Journal of Economic Perspectives 20:3-26.

Decker, R.A., J. Haltiwanger, R.S. Jarmin, and J. Miranda. 2016. "Declining Business Dynamism: What We Know and the Way Forward." In American Economic Review. vol. 106, pp. 203-207. 
Dill, L.M. 1992. "Development and Use Of Industry Data By the Social Security Administration, The." Soc. Sec. Bull. 55:43.

Economics Research Service. 2016. "Agricultural Productivity in the U.S.” Working paper, U.S. Department of Agriculture.

Foster, L., J. Haltiwanger, and C.J. Krizan. 2006. "Market Selection, Reallocation, and Restructuring in the U.S. Retail Trade Sector in the 1990s." The Review of Economics and Statistics 88:748-758.

—. 2002. "The Link Between Aggregate and Micro Productivity Growth: Evidence From Retail Trade.” Working paper, National Bureau of Economic Research.

Giroud, X., and H.M. Mueller. 2015. “Capital and Labor Reallocation Within Firms.” The Journal of Finance 70:1767-1804.

Gourio, F., T. Messer, and M. Siemer. 2016. "Firm Entry and Macroeconomic Dynamics: A State-Level Analysis.” American Economic Review 106:214-218.

Haltiwanger, J., R.S. Jarmin, and J. Miranda. 2013. "Who Creates Jobs? Small Versus Large Versus Young." Review of Economics and Statistics 95:347-361.

Jarmin, R.S., and J. Miranda. 2002. "The longitudinal business database." Available at SSRN 2128793, pp. .

Lee, Y., and T. Mukoyama. 2015. "Entry and Exit Of Manufacturing Plants Over the Business Cycle.” European Economic Review 77:20-27.

Marion, B.W., and Others. 1986. The Organization and Performance Of the U.S. Food System. DC Heath and Company.

Mighell, R.L., and L.A. Jones. 1963. "Vertical Coordination in Agriculture."

Milner, J. 2016. "Everything You Need to Know About the Commission on Evidence-Based Policymaking." http://www.urban.org/urban-wire/ everything-you-need-know-about-commission-evidence-based-policymaking, Accessed: 2016-11-27. 
Oberfield, E., and D. Raval. 2014. "Micro Data and Macro Technology." Working paper, National Bureau of Economic Research.

Prescott, E., and L. Ohanian. 2014. "Behind the Productivity Plunge: Fewer Startups."

Shumway, C.R., B.M. Fraumeni, L.E. Fulginiti, J.D. Samuels, and S.E. Stefanou. 2016. "U.S. Agricultural Productivity: A Review of USDA Economic Research Service Methods." Applied Economic Perspectives and Policy 38:1-29.

Syverson, C. 2004. "Market Structure and Productivity: A Concrete Example." Working paper, National Bureau of Economic Research. 


\section{Figures}

Figure 1: Number of Establishments Classified as Agricultural Support Services for Crop Production by Data Source

Panel A: County Business Patterns (1998-2014) and Quarterly Census of Employment and Wages (2000-2014)

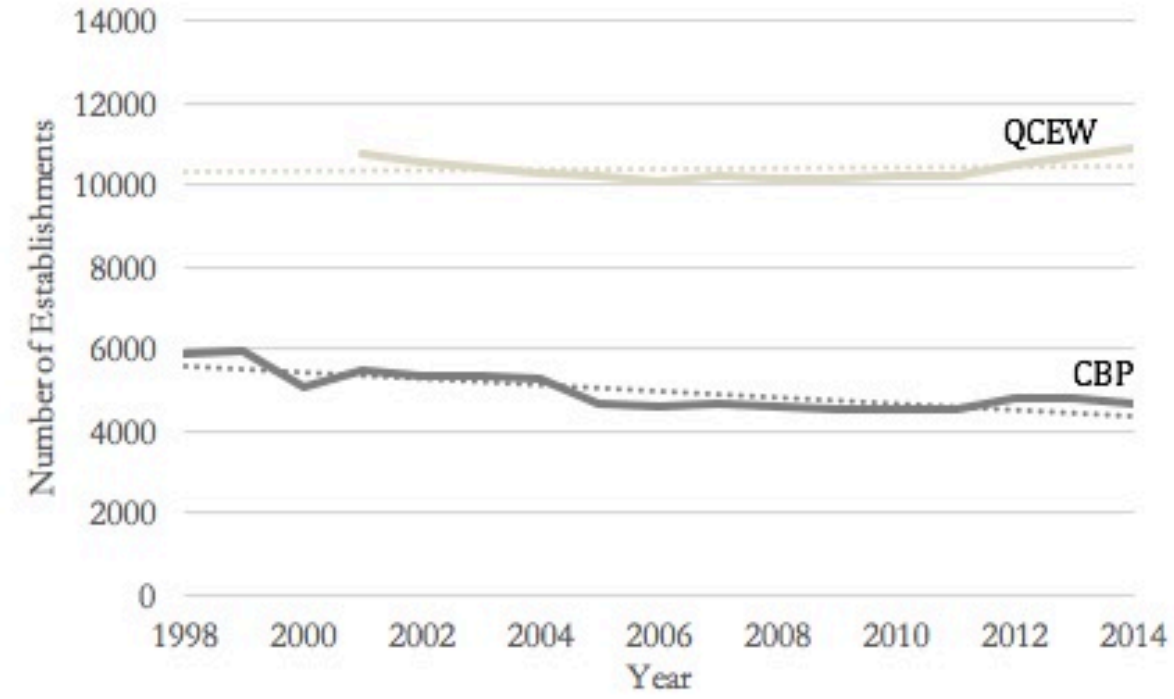

Panel B: Longitudinal Business Database (1998-2012) and Quarterly Census of Employment and Wages (2000-2014)

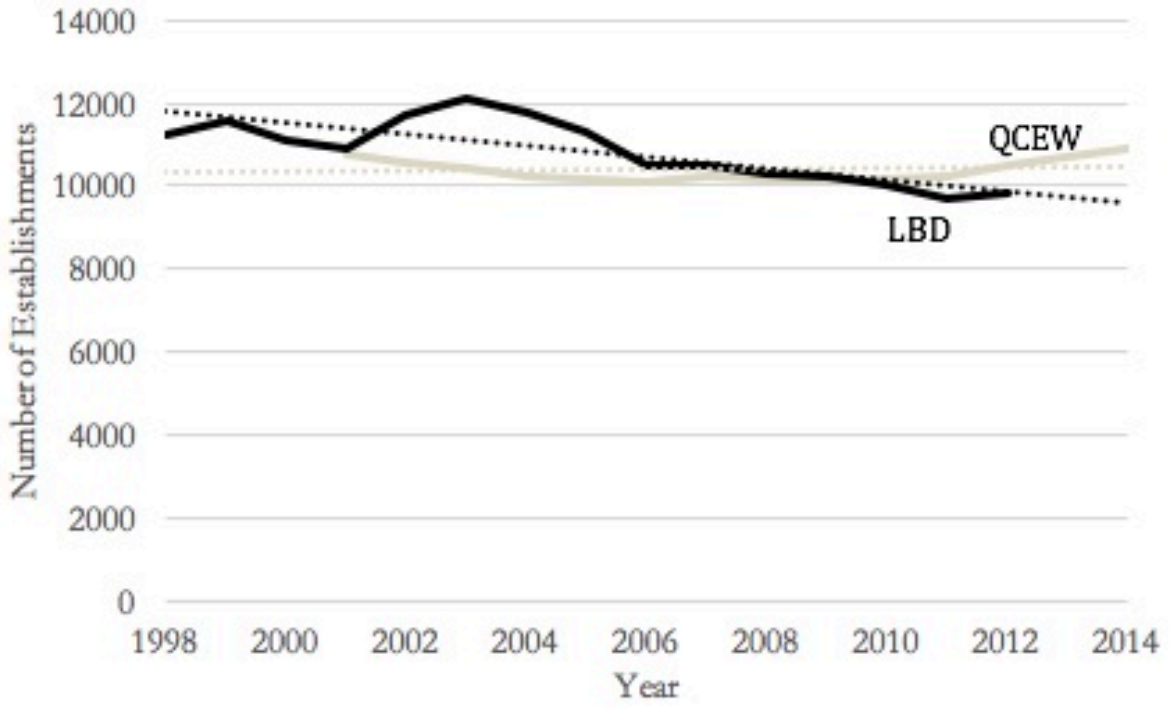


Figure 2: Birth (entry) and Death (exit) rates for Establishments in Agricultural Support Services for Crop Production

Panel A: Establishments ever assigned to Agricultural Support Services for Crop Production (NAICS 1151)

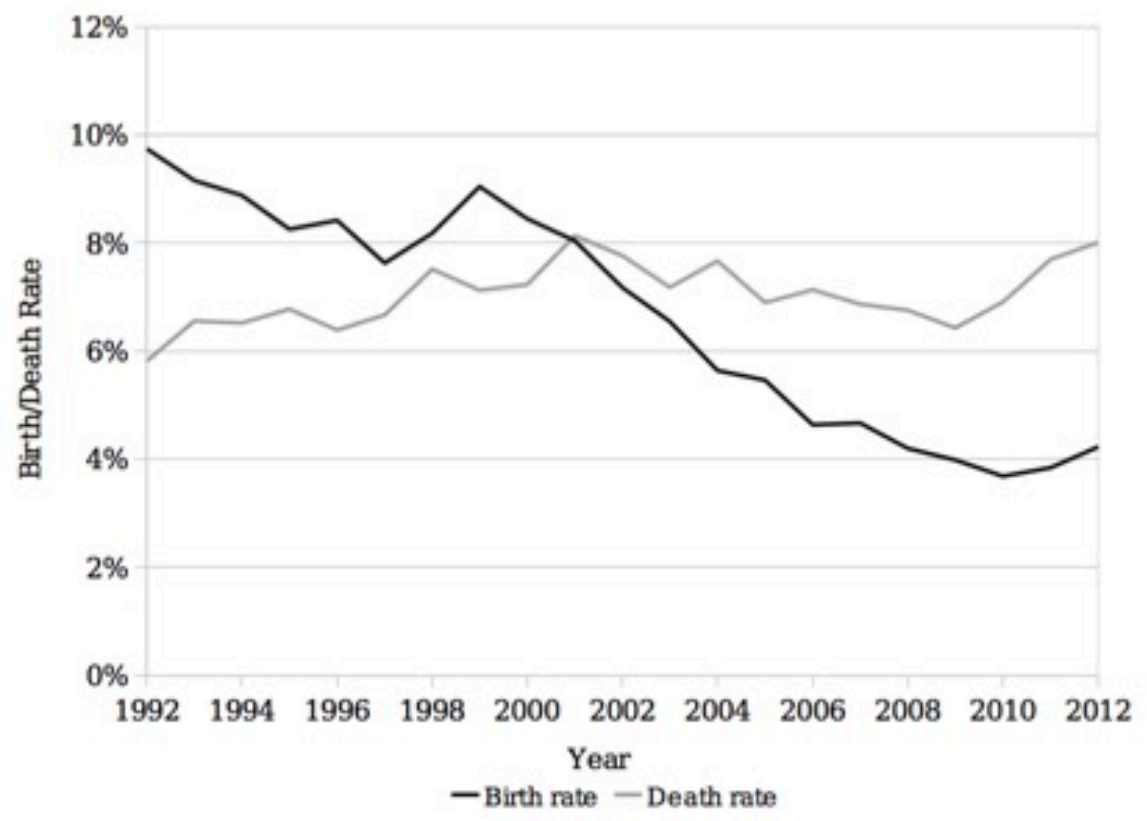

Panel B: Establishments assigned to Agricultural Support Services for Crop Production in Year of Birth or Year of Death (NAICS 1151)

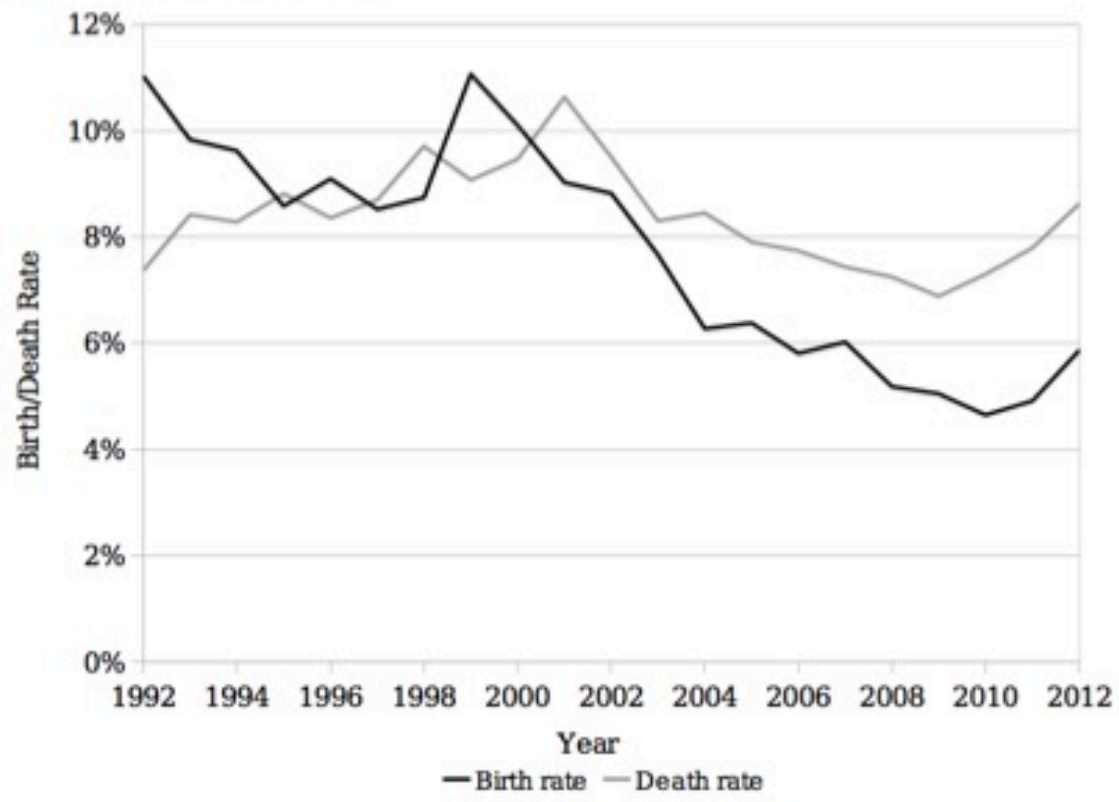

Note: Birth and death rates calculated from Longitudinal Business Database. 
Figure 3: Mean Employees per Establishment in Agricultural Support Services for Crop Production (NAICS 1151) by Data Source and Time of Year.

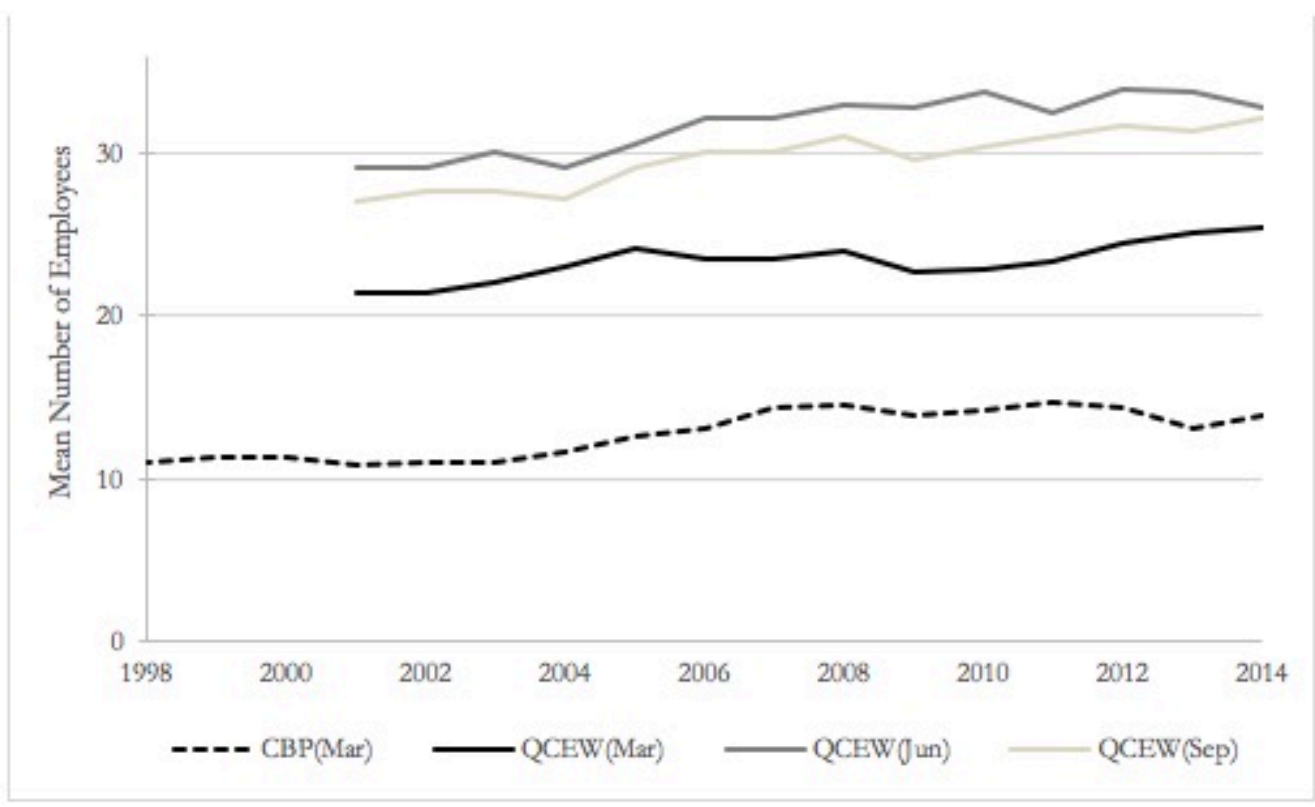


Figure 4: Proportion of Establishments in Agricultural Support Services for Crop Production (NAICS 1151) from Multi-establishment Firms: 1992-2012.

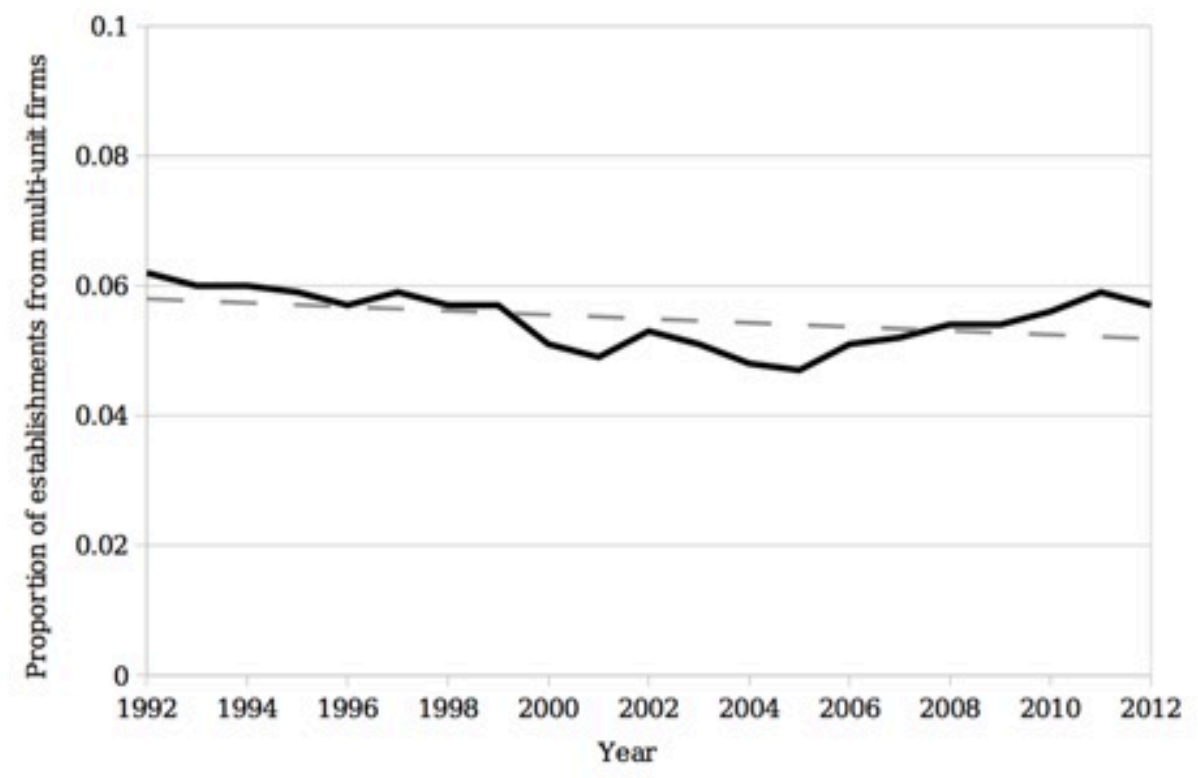

Note: Calculated from the Longitudinal Business Database. The slope of the trend line is -0.03 percentage points per year with a standard error of 0.01 percentage points $(p<0.047)$. 


\section{Tables}

\section{Table 1. List of Abbreviations}

\begin{tabular}{ll}
\hline ARS & Annual Refiling Survey \\
AS & agricultural support services \\
BDS & Business Dynamics Statistics \\
BLS & Bureau of Labor Statistics \\
CBP & County Business Patterns \\
CES & Census Bureau Center for Economic Studies \\
COS & Company Organization Survey \\
EIN & employer identification numbers \\
FAI & food and agriculture industries \\
FSRDC & Federal Statistical Data Research Center \\
FUTA & Federal Unemployment Tax Act \\
IRS & Internal Revenue Service \\
LBD & Longitudinal Business Database \\
LED & Local Employment Dynamics \\
LEHD & Longitudinal Employer-Household Dynamics \\
NAICS & North American Industry Classification System \\
NASS & National Agricultural Statistics Service \\
NAWS & National Agricultural Workers Survey \\
QCEW & Quarterly Census of Employment and Wages \\
QWI & Quarterly Workforce Indicators \\
SSA & Social Security Administration \\
UI & unemployment insurance \\
\hline
\end{tabular}




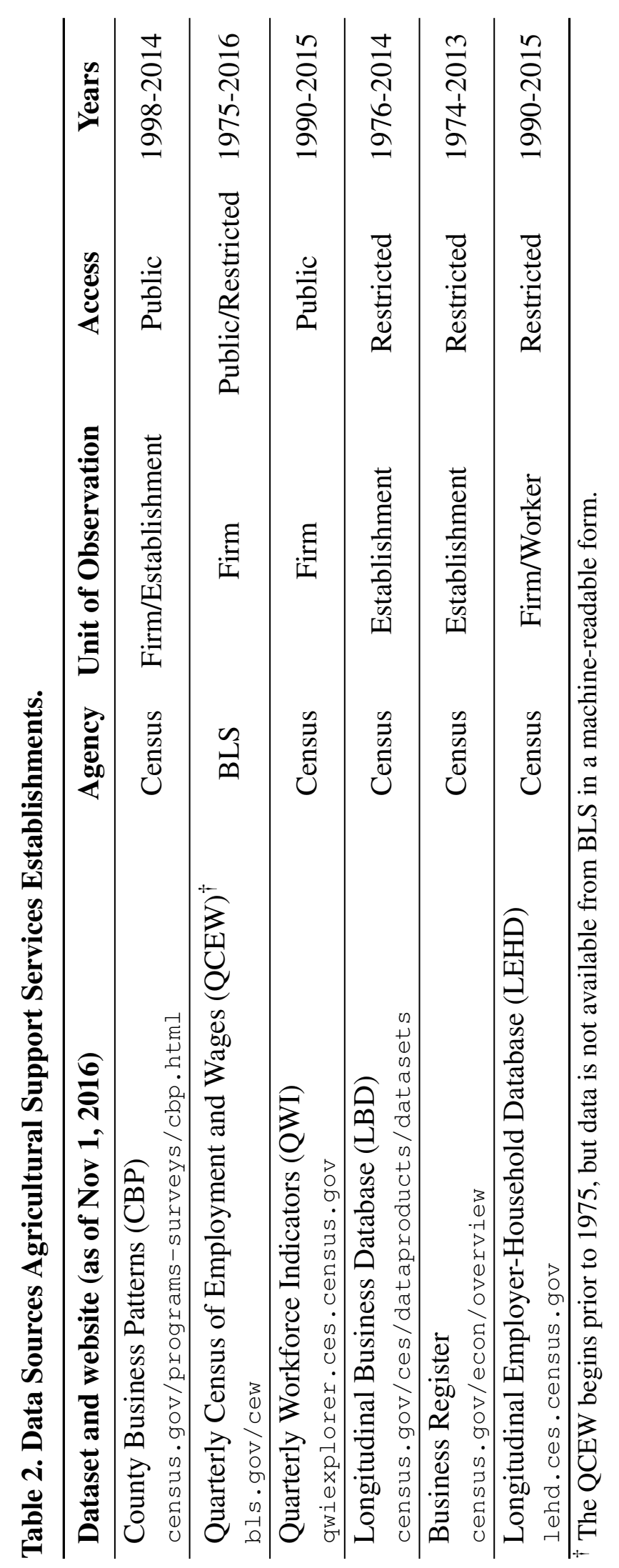

